\title{
Covid-19 Vaccination - A Saviour from Pandemic
}

\author{
Riya Bhargava ${ }^{1}$, Anurag Ghiloria² ${ }^{\text {, Poorvi Kapoor }}{ }^{3}$, Sameera Dawar ${ }^{4}$ Nisha Rani Yadav5 ${ }^{5}$ Meena Jain ${ }^{6}$
}

1, 2, 3, 4, 5, 6 Department of Public Health Dentistry, Manav Rachna Dental College, FDS, MRIIRS Faridabad, Haryana, India.

\section{ABSTRACT}

\section{BACKGROUND}

The world is hit by a global pandemic caused by severe acute respiratory syndrome coronavirus, a new genotype of the virus, which causes coronavirus disease, Covid19. The situation has challenged the entire scientific community nationally as well as internationally to fight back this deadly disease. Since its beginning in November 2019 , it has disseminated throughout the human race, regardless of all the measures taken by healthcare sectors, governments, and world health organizations as well. Numerous investigations show that this virus uses air as a passage to commute and spread, the disease most commonly spreads through droplet infections and when comes in contact with the mucous membrane, enters the body. Entire medical staff along with scientists of various nations are working perpetually to develop successful vaccines and drugs to fight back this virus. Amongst various vaccines developing across the world, many of them are in their clinical trials and human trial phases and those which have succeeded in all the trial phases are getting delivered to citizens since December 2020. The present article aims to provide a review of the literature on the type of vaccinations that have been developed so far with their mechanism of action and their basic formulations.

\section{KEY WORDS}

Pandemic, SARS-CoV-2, Vaccine, Coronavirus, Antibody, Immunization, COVID-19
Corresponding Author: Dr. Nisha Rani Yadav, House no. 339, Sec-21, Gurgaon, Haryana, India. E-mail: drnisharao@gmail.com

DOI: $10.14260 / \mathrm{jemds} / 2021 / 693$

How to Cite This Article:

Bhargava R, Ghiloria A, Kapoor P, et al. Covid-19 vaccination - a saviour from pandemic. J Evolution Med Dent Sci 2021;10(38):3424-3429, DOI: $10.14260 / \mathrm{jemds} / 2021 / 693$

Submission 18-06-2021, Peer Review 26-08-2021, Acceptance 03-09-2021, Published 20-09-2021.

Copyright (C) 2021 Riya Bhargava et al. This is an open access article distributed under Creative Commons Attribution License [Attribution 4.0 International (CC BY 4.0)] 


\section{BACKGROUND}

Coronavirus was first identified in the early 1960s and was named so due to its crown-shaped body. The coronavirus disease (Covid-19) has wreaked havoc and disrupted lives significantly worldwide. It is the upgraded form of infection similar to severe acute respiratory syndrome coronavirus 2 (SARS-CoV-2) ${ }^{1}$ which was initially seen in a small city of China, Wuhan, during December 2019.2,3 Many investigations prove that genetically SARS-CoV-2 is $70 \%$ similar to SARS-CoV and Middle East respiratory syndrome coronavirus (MERS-CoV), 4,5 which is now increasing through human transmission in the form of small droplets from the air. ${ }^{1}$ It is believed to have caused a zoonotic spread from bats to humans. The virus is typically known to spread by the inhalation of infected respiratory droplets, it is, therefore, essential to maintain social distancing in public places and always maintain personal barrier protection with masks, face shields, etc. Additionally, the infection may spread by contacting contaminated surfaces and subsequently touching eyes, mouth, nose, etc. Maintaining personal hygiene by frequently washing hands, wearing gloves, using alcohol-based hand rub, etc., is extremely essential to minimize the risk of infection.

The severity of the infection may range from mild flu-like symptoms to severe respiratory distress or even death. At times the patients may even remain asymptomatic. The case fatality rate of Covid-19 is estimated to be around $2 \%-4 \%$, whereas it was found to be approximately $10 \%$ for SARS and $40 \%$ for MERS. However, the pandemic linked with Covid-19 has been unquestionably more severe. ${ }^{1}$ As of March 15, 2020, SARS-CoV-2 had transmitted quickly to 34 towns and cities in China; and cases have been reported in 144 countries.1,6 Whereas comparing this with today's statistics, it has hit every part of the world leaving us in a global pandemic. The Covid19 pandemic has come up with considerable threats for everyone including every entity be it our authorities, individuals, or community as a whole..$^{7,8}$ The coronaviruses are heat sensitive and might lose their structural form at $56^{\circ} \mathrm{C}$ when heated for 30 minutes. Additionally, they are also sensitive to other solvents such as ethanol (75\%), ether, chlorine-based disinfectants, peroxyacetic acid, chloroform, etc. Other lipid-based solvents may also effectively inactivate the virus. ${ }^{9,10}$ While there are many ways to minimize the risk of getting infected, immunization in the form of vaccination against the disease is the only and most efficient mode of protection.

\section{VACCINE AND ITS PROGRESS}

The quick speed of development of vaccinations against Covid19 is enabled by some components including previous data on the job of the S-protein in Covid pathogenesis. Pieces of evidence regarding the elimination of counteracting agents against the spike protein are remarkable for the insusceptibility of the virus. ${ }^{11,12}$ Most of the vaccines being produced and tested today are based on the spike (S) protein structure. However, with medical science advancing each day, other vaccine forms may be introduced in the future. The 5 year-long quest for the production of a safe and effective vaccine against Mumps, has been the fastest in history so far.
Along these lines, it is a challenge to produce a vaccine for Covid-19 out of scope of 12 years. ${ }^{13,14}$

The primary stage of the immunization progression is an exploratory stage including fundamental lab investigations and estimations showing to perceive normal or designed antigens that can be used as an inoculation up-and-comer, which may help hinder or treat an affliction. ${ }^{15}$

The second stage involves pre-clinical assessments that incorporate cell-culture or tissue-culture-based inoculation trials on the animal model to demonstrate and observe the outcome of the prepared inoculation to overview its resistance and efficacy. The results are then used as the basis to determine whether the preparation is fit for the next stage of testing. ${ }^{13}$

\section{Immune Response to the Virus and Need of a Vaccine}

When a foreign body like a virus or bacteria invades the host body it triggers an immune response by increasing the production of certain inflammatory factors, and synthesis of type 1 interferons (IFNs) which in turn helps in controlling the spread of the disease in the host body. ${ }^{16}$

\section{Pathogenesis}

Although the pathogenesis of coronavirus disease is still unknown some studies suggest that when SARS-CoV-2 enters through the nasal passage it is encountered by ACE - II (angiotensin-converting enzyme - II) receptors present on the surface of respiratory epithelium. After entering into these cells the virus replicates and releases out to invade other cells around. This activates the host's innate immune response and $\mathrm{T}$ - cells production starts. Dendritic cells also get activated and start maturing through certain receptors. The inflammatory response is then stimulated in the body by releasing interferons (IFN - $\alpha$, IFN - $\gamma$ ), interleukins (IL - $1 \beta$, IL - 6, IL - 12, IL - 18, IL - 33), TNF $\alpha$, TGF - $\beta$, CCL2, CCL3, CXCL8, CXCL9, CXCL10, ROC, NO and increasing the phagocytic cell activities resulting in recovery from the infection. 16

Sometimes the virus can escape from the immune response due to the presence of $\mathrm{N}$ - protein, this, in turn, results in overproduction of inflammatory mediators and free radicals which can cause local tissue damage (sometimes severe) in the lungs especially, multi-organ dysfunction and failure and can be fatal also. ${ }^{16}$

Adaptive immunity is another type of immune response, being, activated by antigen-presenting cells like dendritic cells also helps in combating the virus. The main type of cells in this response is the $\mathrm{T}$ lymphocytes in the form of CD4+ and CD8+ $\mathrm{T}$ cells. CD4+(T - helper cells) stimulate $\mathrm{B}$ cells to produce antibodies against the virus and on the other hand, CD8+ T cells directly act upon the virus-infected cells and eradicate them. The $\mathrm{T}$ - helper cells or $\mathrm{CD} 4+$ cells also produce inflammatory cytokines. However, in certain cases, the harmful SARS-CoV-2 can block $\mathrm{T}$ cells by inducing cell apoptosis. ${ }^{16}$ Humoral immunity also aids in fighting against the infection by releasing $\mathrm{C} 3 \mathrm{a}$ and $\mathrm{C} 5 \mathrm{a}$ complement factors. When the virus acts upon the plasma cells, they produce IgG and IgM antibodies in the host body. 16

\section{Immunological Memory}

Only the affected cells are removed after a primary immune response in the body but the antibodies thus produced after it 
remains in the host body along with memory $\mathrm{B}$ and $\mathrm{T}$ cells when an individual is immunized against an antigen the helper $\mathrm{T}$ cells and $\mathrm{B}$ cells memory against it. After that, if the same antigen is presented again, firstly the helper $\mathrm{T}$ cells appear in huge numbers followed by the antigen-specific B cells. This is called the secondary immune response. After approximately 30 days of immunization, the number of $B$ cells is at its maximum and is maintained for a lifetime with slight modifications in quantity over time. ${ }^{17}$

\section{Components of a Vaccine}

1. Antigen - It is any toxin or foreign body / substance / material which when enters the host cell body, helps in the production of antibodies against the same pathogen it was derived from. It can be anything from a virus, bacteria, microbe, chemical, pollen, etc. Based on the nature of antigen introduced in the body, vaccines can be of the following types 18

- Live attenuated vaccines

- Inactivated vaccines

- Subunit type vaccine

- Peptide-based vaccine

2. Adjuvant - it is a stimulatory component that helps to boost host response against the antigen ${ }^{18}$

3. Nanoparticle / nanocarrier - It can be understood as a very small quantity of a live or inactivated virus itself which can be used as a carrier to enfold the antigen's body or only the nucleic acid which is encoding for the antigen. Based on this, nanoparticles can be a viral vector, protein nanoparticle, and synthetic nanoparticle ${ }^{18}$

4. A device is used for the smooth dispensing and delivery of vaccines. They can be: a syringe, an implant, microneedle, etc. 18

\begin{tabular}{|c|c|}
\hline Phase & Aim \\
\hline Exploratory phase & Vaccine development \\
\hline Preclinical & $\begin{array}{l}\text { Vaccine turned out to be immunogenic and the initial } \\
\text { doses for humans started to rule out }\end{array}$ \\
\hline Clinical Trial phase & Started human experimenting \\
\hline Phase I & $\begin{array}{l}\text { First-in-human testing. Vaccine safety and immune } \\
\text { response in humans to be checked }\end{array}$ \\
\hline Phase II & $\begin{array}{l}\text { Vaccine safety, immunity / partial efficacy. Dose- } \\
\text { response, schedule, and method of delivery }\end{array}$ \\
\hline $\mathrm{Pl}$ & Vaccine efficacy and safety \\
\hline Biologic Lice & Marketing of \\
\hline Phase IV & Postmarketing surveillance \\
\hline \multicolumn{2}{|c|}{$\begin{array}{l}\text { Table 1. Stages Considered during Covid Vaccine Development } \\
\text { Phases }{ }^{19}\end{array}$} \\
\hline
\end{tabular}

\section{Diversity of Technology Platforms}

A striking element of the antibody improvement scene for Covid-19 is the scope of innovation stages being assessed, including nucleic corrosive (DNA and RNA), infection-like molecule, peptide, viral vector (repeating and nonduplicating), recombinant protein, live constricted infection, and inactivated infection draws near. ${ }^{20}$

A considerable lot of these stages are not presently the reason for authorized antibodies, but rather experience in fields, for example, oncology is urging designers to abuse the chances that cutting-edge approaches offer for sped-up advancement and assembling. Some antibody stages might be more qualified to explicit populace subtypes (like the older, youngsters, pregnant ladies, or immune-compromised patients). ${ }^{21}$

\section{THE PIPELINE OF SARS COVID 19 VACCINATIONS}

As per WHO, there are more than 100 vaccines against coronavirus in their different phases of development. Various kinds of antibodies incorporate mRNA vaccines, DNA antibodies, viral vector vaccines, inactivated infection vaccines and another antibody draws near. These vaccines predominantly follow up on SARS Coronavirus body structure.22

\section{mRNA Vaccine}

mRNA antibodies address a promising option in contrast to traditional immunization approaches on account of their high power, limit with regards to fast turn of events, and potential for minimal effort production and safe organization. To proceed with progress on this likely immunization during the continuous worldwide general wellbeing crisis, Moderna company has worked with the FDA and various other government and non-government associations ${ }^{15}$ for preparation of stage 2 of the vaccine development process and any ensuing trials, which are foreseen to incorporate an enormous number of subjects and have produced extra safe and immunogenic information. ${ }^{23}$

Apart from this, BioNTech and Pfizer have also mutually built up another mRNA antibody (BNT162), which has been endorsed for a 1 / 2 stage clinical trial to decide the ideal dose for additional investigations just as to assess the safety and immunogenicity of the immunization. It is principally the firstever clinical trial of a Covid-19 vaccination to begin in Germany and is an important step for a worldwide advancement and safety program. ${ }^{15}$

\section{DNA Vaccine}

These are mainly in use with arising irresistible infections since they take into consideration the quick plan of different possibilities for novel antigens. ${ }^{24}$ Moreover, they are straightforwardly infused or in any case, immunized into people. As of late, different DNA immunization stages are being created to improve the viability of antibodies by electroporation (EP), a method to convey plasmids and adding adjuvants to upgrade resistant reactions. ${ }^{15}$

INOVIO Pharmaceuticals and organizations were the first to progress their vaccine against MERS - CoV25 INO - 4800,15 a DNA vaccine almost like coronavirus, into assessment amongst people, and this organization has built up a DNA antibody (INO - 4800) to forestall disease by SARS-CoV-2. INO - 4800 instigates T cell initiation by introducing DNA plasmids into the virus that express the SARS-CoV-2 S protein. As result, the functional antibodies and antigen-specific $\mathrm{T}$ cells show up and give results. The reactionary results in different animals are especially reassuring. ${ }^{26}$

\section{Viral Vector Vaccine}

Viral vector vaccines are a combination of recombinant viruses which use antigens of interest in an unrelated modified virus genome, ${ }^{8}$ usually depending on a host viral genome, it is designed to conceal antigenic segments of infection important to get a resistant reaction. Since viral vector vaccines endure in the body of the host as genes, they straightforwardly 
contaminate antigen-introducing cells and have strong responses, effectively inciting $\mathrm{B}$ cell - and $\mathrm{T}$ cell-mediated resistant reactions. Besides, popular vector antibodies can bring about high-titre neutralizing antibodies. ${ }^{15,27}$

A few distinctive viral vaccines have been created as SARS CoV-2 vaccines. ${ }^{15}$ CanSinoBIO and the Beijing Institute of Biotechnology (BIB) have teamed up to build an adenovirus type 5 viral vector-based Covid vaccine Ad5 - $\mathrm{nCoV}$ that has the full-length S protein of SARS-CoV-2. Ad5 - $\mathrm{nCoV}$ is developed against SARS-CoV-2 virus by using a recombinant and poorly replicating human adenovirus type - 5 vectors to incite the desired reaction. The vaccine created is similar to CanSino BIO's adenovirus-based viral vector antibody innovation stage, which has also been successfully used to create a universally creative antibody against the Ebola virus disease. The outcomes from preclinical investigations of this vaccine show that the antibody up - and - comer can actuate a solid safe reaction in creature models, and preclinical creature wellbeing examines exhibit a decent security profile. ${ }^{15}$

A first-in-human trial revealed that the Ad5 - $\mathrm{nCoV}$ antibody is passable and immunogenic in fit individuals, 15,28 with explicit humoral reactions against SARS-CoV-2 cresting at day 28 after vaccination and fast explicit $\mathrm{T}$ - cell reactions noted at day 14. There is still some hope for an additional examination of the Ad5 - nCoV immunization for managing the Covid-19 flare-ups. Besides, University of Oxford specialists has started trials for another Covid-19 immunization called ChAdOx1 nCoV - 19; it is gotten from an infection (ChAdOx1) that is a weakened form of a typical cold infection (adenovirus) causing diseases in chimpanzees, yet it has been hereditarily altered to such an extent that it can't multiply in people. 15 The antibody depends on an adenovirus vector (ChAdOx1) and the SARS-CoV-2 S protein. The outcomes showed that a solitary inoculation with ChAdOx1 nCoV - 19 is compelling with forestalling lung harm upon increased - portion challenge with SARS-CoV-2.29,15

\section{Protein Subunit Vaccine}

Recombinant - protein-based vaccines are beneficial over different sorts of antibodies in that they are protected and do not have many results, prompting the resistant framework without the presentation of irresistible infections. One of them is NVX - CoV2373 antibody created by Novavax, right now in its clinical stage. ${ }^{30}$

That was developed by utilizing recombinant nanoparticle innovation to produce antigen got from the $S$ protein and contains Matrix - $\mathrm{M}^{\mathrm{TM}}$ adjuvant to upgrade the invulnerable reaction and invigorate significant degrees of killing antibodies. ${ }^{15} \mathrm{~A}$ trial of Clover's S - trimer antibody created by Clover Biopharmaceutical solid grown-ups in Australia, and this immunization will be generally endless supply of its wellbeing and adequacy. Also, LV - SMENP - DC and microbe explicit aAPC vaccines from Shenzhen Geno - Immune Medical Institute are in stage 1 clinical trials to assess security and safe reactivity. ${ }^{31,32}$

\section{Other Vaccine Approaches}

This incorporates live-constricted vaccines that are created by diminishing or wiping out the harmfulness of a live virus, regularly utilizing synthetic driven or site-coordinated mutagenesis. In this manner, the infection is fit for profitable contamination, yet the subsequent sickness is either decreased or wiped out. Live-lessened vaccines can inspire both inborn and versatile resistant reactions, and insurance can be deep-rooted. Furthermore, their creation is reasonable. Codagenix and the Serum Institute of India are utilizing viral deoptimization to combine "reasonably planned", livingconstricted antibodies for the new Covid.15,33

\section{Contraindications ${ }^{34}$}

- If a previous dosage of Covid-19 vaccination caused an anaphylactic or allergic response.

- Allergic response to any other vaccination or injectable therapies, food items, or pharmaceutical products.

- Lactating and pregnant women

- Persons with the symptoms of SARS-CoV-2 infections.

- SARS-CoV-2 patients who have received convalescent plasma or monoclonal antibodies.

In persons with a history of coagulation and bleeding disorder, vaccines should be administered with caution. Conditions that are not contraindicated:

- Immunosuppressed or Immunodeficient patients.

- People with a history of Covid-19 infection (after a threemonth recovery period).

- Individuals who have a history of comorbidities or chronic diseases.

\author{
Side Effects ${ }^{35}$ \\ - Pain at the injection site \\ - Fever \\ - Fatigue \\ - Headache \\ - Muscle pain \\ - Chills \\ - Tiredness
}

\section{Adverse Effects of Vaccine ${ }^{36}$}

Though rare, vaccination can cause

- Thrombosis with thrombocytopenia syndrome.

- Anaphylaxis

- Myocarditis and pericarditis

- Death

\begin{tabular}{|c|c|c|}
\hline $\begin{array}{l}\text { Vaccine } \\
\text { Strategy }\end{array}$ & Candidates & $\begin{array}{c}\text { Lead Developer among Different } \\
\text { Nations }\end{array}$ \\
\hline \multirow{2}{*}{ RNA Vaccines } & mRNA - 1273 & Moderna / NIAID \\
\hline & BNT162 & BioNTech / Fosun Pharma / Pfizer \\
\hline \multirow{2}{*}{$\begin{array}{l}\text { Viral vector- } \\
\text { based vaccines }\end{array}$} & Ad5 - nCoV & $\begin{array}{c}\text { CanSino Biological Inc., Beijing Institute } \\
\text { of Biotechnology }\end{array}$ \\
\hline & ChAdOx1 nCoV - 19 & University of Oxford \\
\hline DNA vaccines & INO -4800 & INOVIO Pharmaceuticals \\
\hline \multirow[t]{2}{*}{$\begin{array}{c}\text { Inactivated } \\
\text { virus vaccines }\end{array}$} & Inactivated virus & $\begin{array}{l}\text { Beijing Institute of Biological Products / } \\
\text { Wuhan Institute of Biological Products } \\
\text { Institute of Medical Biology, Chinese } \\
\text { Academy of Medical Sciences }\end{array}$ \\
\hline & Inactivated & Sinovac \\
\hline Protein subunit & NVX - CoV2373 & Novavax \\
\hline
\end{tabular}

\section{VARIOUS VACCINES SO DEVELOPED}

Since the beginning of this pandemic, different vaccines have been developed around the world and a majority of them are in their application phase. A large population has been 
successfully vaccinated all over the world with the right ones. Some of the vaccines authorized / approved so far are listed below. $21,37,38$

A. mRNA Based Vaccines -

1. COMIRNATY (BNT162b2): a multinational approved vaccine and,

2. Moderna Covid-19 Vaccine (mRNA - 1273): which is a USbased vaccine

3. $\mathrm{CVnCoV} \mathrm{/} \mathrm{CV07050101:} \mathrm{Vaccine} \mathrm{encapsulated} \mathrm{in} \mathrm{a} \mathrm{lipid}$ nano molecule.

B. Inactivated Virus Vaccine:

1. BBIBP - CorV - produced and developed by Sinopharm's Beijing Institute of Biological Products, China

2. CoronaVac (formalin with adjuvant alum) - the primary producer in China

3. Covaxin- from India

4. Covivac- from Russia are also of this type

C. Recombinant Adenovirus Vaccine -

1. Convidicea (Ad5 - nCoV) - Recombinant adenovirus type 5 vector vaccine, originated in China, primary developers - CanSino Biologics

2. ZF2001 - originated by China and Uzbekistan

3. CoV2preSdTM - AS03 vaccine - manufactured by Sanofi Pasteur, France

4. AstraZeneca (AZD1222) - manufactured by AstraZeneca, University of Oxford, UK.

5. Sputnik V - Human adenovirus vector recombinant type of vaccine (rAd26 and rAd5), A Russian based vaccine

6. Covishield (ChAdOx1_nCoV - 19) - By Serum Institute of India

7. Ad26.COV2. S - by Janssens Group

D. Non-Replicating Viral Vector

1. Janssen Covid-19 Vaccine (JNJ - 78436735; Ad26.COV2.S) - primarily developed by Johnson \& Johnson, Netherlands, US

E. Peptide Vaccine

1. EpiVacCorona - Primarily developed by Federal Budgetary Research Institution State Research Centre of Virology and Biotechnology, Russia

F. Protein Subunit Vsaccines

1. Recombinant Novel Coronavirus Vaccine - CHO Cell type, developed by Zhifei Longcom company, China

2. NVX - CoV2373: Recombinant nanoparticle, spike protein-based vaccine with matrix adjuvant manufactured by Novavax

3. SCB - 2019 - recombinant SARS-CoV-2 Spike (S) - Trimer fusion protein-based vaccine by Clover Biopharmaceuticals

\section{CONCLUSIONS}

The coronavirus disease 2019 (Covid-19) has presented major threats to the community all over the world. While numerous efforts have been made by scientists and healthcare professionals worldwide to develop a vaccine since the beginning of the pandemic, the quest to produce a safe and efficacious vaccine against the upcoming viral mutations continue. The speed with which various vaccines have been developed and some under process are truly worth all the praise. This article provides a review on the various types of Covid-19 vaccines available, their mechanism of action and basic formulations, and how to get yourself vaccinated with one based on the available literature. Till the whole population is immunized against the virus, it continues to pose a substantial threat to mankind. As of today, different vaccination platforms have been created to improve the viability of antibodies to dismiss resistant reactions in patients. Some antibody stages might be more qualified to explicit populace subtypes. Various successful vaccinations are being conducted in different countries to control the disease, many are still under development, as with each day passing, the deadly virus is coming up with new symptoms and complications. But the new challenge for the governments is the production of trillions of doses of Covid-19 vaccines among the citizens with the target of good immune response in vaccinated individuals which can take at least 1 to 2 years to stop the spread of severity of this virus.

Financial or other competing interests: None.

Disclosure forms provided by the authors are available with the full text of this article at jemds.com.

\section{REFERENCES}

[1] Levin AT, Hanage WP, Owusu-Boaitey N, et al. Assessing the age specificity of infection fatality rates for COVID - 19: systematic review, meta-analysis and public policy implications. Eur J Epidemiol 2020;35(12):1123-38.

[2] Zhu N, Zhang D, Wang W, et al. A novel coronavirus from patients with pneumonia in China, 2019. N Engl J Med 2020;382(8):727-33.

[3] Liu Z, Magal P, Seydi O, et al. Understanding unreported cases in the COVID-19 epidemic outbreak in Wuhan, China and the importance of major public health interventions. Biology 2020;9(3):50.

[4] Hu B, Guo H, Zhou P, et al. Characteristics of SARS-CoV-2 and COVID-19. Nat Rev Microbiol 2021;19(3):141-54.

[5] Petrosillo N, Viceconte G, Ergonul O, et al. COVID-19, SARS and MERS: are they closely related? Clin Microbiol Infect 2020;26(6):729-34.

[6] World Health Organization. World health organization coronavirus disease 2019 (COVID-19) weekly epidemiological update and weekly operational update. Situation Report 2020.

[7] Ahmed S, Taqi HMM, Farabi YI, et al. Evaluation of flexible strategies to manage the COVID-19 pandemic in the education sector. Global Journal of Flexible Systems Management 2021:1-25.

[8] Li YD, Chi WY, Su JH, et al. Coronavirus vaccine development: from SARS and MERS to COVID-19. J Biomed Sci 2020;27(1):104.

[9] Xu K, Lai X, Liu Z. Suggestions on the prevention of COVID19 for health care workers in department of otorhinolaryngology head and neck surgery. World J Otorhinolaryngol Head Neck Surg 2020;6(Suppl 1):S2-5. 
[10] Wang H, Li X, Li T, et al. The genetic sequence, origin and diagnosis of SARS-CoV-2. Eur J Clin Microbiol Infect Dis 2020;39(9):1629-35.

[11] Sorgel F. COVID-19 vaccine development. J Bioequiv Availab 2020;12:408.

[12] Belete TM. A review on promising vaccine development progress for COVID-19 disease. Vacunas 2020;21(2):1218.

[13] Sharma O, Sultan AA, Ding H, et al. A review of the progress and challenges of developing a vaccine for COVID-19. Front Immunol 2020;11:585354.

[14] Abd El-Aziz TM, Stockand JD. Recent progress and challenges in drug development against COVID-19 coronavirus (SARS-CoV-2)-an update on the status. Infect Genet Evol 2020;83:104327.

[15] Liu X, Liu C, Liu G, et al. COVID-19: progress in diagnostics, therapy and vaccination. Theranostics 2020;10(17):7821-35.

[16] Mortaz E, Tabarsi P, Varahram M, et al. The immune response and immunopathology of COVID-19. Front Immunol 2020;11:2037.

[17] Wikipedia. Immunological memory. Wikipedia 2021. (Retrieved 20 June 2021) https://en.wikipedia.org/wiki/Immunological_memory

[18] Shin MD, Shukla S, Chung YH, et al. COVID-19 vaccine development and a potential nanomaterial path forward. Nat Nanotechnol 2020;15:646-55.

[19] Khuroo MS, Khuroo M, Khuroo MS, et al. COVID-19 vaccines: a race against time in the middle of death and devastation! J Clin Exp Hepatol 2020;10(6):610-21.

[20] Chen T, Peng L, Jing B, et al. The impact of the COVID-19 pandemic on user experience with online education platforms in China. Sustainability 2020;12(18):7329.

[21] Le TT, Andreadakis Z, Kumar A, et al. The COVID-19 vaccine development landscape. Nat Rev Drug Discov 2020;19(5):305-6.

[22] Rawat K, Kumari P, Saha L. COVID-19 vaccine: a recent update in pipeline vaccines, their design and development strategies. Eur J Pharmacol 2021;892:173751.

[23] Pardi N, Hogan MJ, Porter FW, et al. mRNA vaccines-a new era in vaccinology. Nat Rev Drug Discov 2018;17(4):26179.

[24] Lee J, Kumar SA, Jhan YY, et al. Engineering DNA vaccines against infectious diseases. Acta Biomater 2018;80:31-47.

[25] Modjarrad K, Roberts CC, Mills KT, et al. Safety and immunogenicity of an anti-Middle East respiratory syndrome coronavirus DNA vaccine: a phase 1, openlabel, single-arm, dose-escalation trial. Lancet Infect Dis 2019;19(9):1013-22.

[26] Yang ZY, Kong WP, Huang Y, et al. A DNA vaccine induces SARS coronavirus neutralization and protective immunity in mice. Nature 2014;428(6982):561-4.

[27] Corey L, Mascola JR, Fauci AS, et al. A strategic approach to COVID-19 vaccine R\&D. Science 2020;368(6494):94850.

[28] Zhu FC, Li YH, Guan XH, et al. Safety, tolerability and immunogenicity of a recombinant adenovirus type-5 vectored COVID-19 vaccine: a dose-escalation, open-label, non-randomised, first-in-human trial. Lancet 2020;395(10240):1845-54.

[29] Van Doremalen N, Lambe T, Spencer A, et al. ChAdOx1 nCoV-19 vaccine prevents SARS-CoV-2 pneumonia in rhesus macaques. Nature 2020;586(7830):578-82.

[30] Novavax initiates phase $1 / 2$ clinical trial of COVID-19 vaccine. NOVAVAX. Revised 25 May 2020.

[31] Safety and immunity of Covid-19 aAPC vaccine. ClinicalTrials.gov. Revised 9 March 2020.

[32] Lurie N, Saville M, Hatchett R, et al. Developing Covid-19 vaccines at pandemic speed. $\mathrm{N}$ Engl J Med 2020;382(21):1969-73.

[33] Immunity and safety of Covid-19 synthetic minigene vaccine. ClinicalTrials.gov. Revised 19 Febryary 2020.

[34] Wikaspedia Domains. 2021 Retrieved 20 June 2021. https://vikaspedia.in/health/health-campaigns/allbout-covid-vaccines/precautions-and-contraindicationsfor-covid19-vaccination

[35] Side effects of COVID-19 vaccines. World Health Organisation 2021. https://www.who.int/newsroom/feature-stories/detail/side-effects-of-covid-19vaccines

[36] Selected adverse events reported after COVID-19 vaccination COVID-19 vaccination. Centers for Disease Control and Prevention 2021. https://www.cdc.gov/coronavirus/2019-ncov/ vaccines/ safety/ adverse-events.html

[37] Jeff C. COVID-19 therapeutics tracker. Regulatory Focus 2020. https://www.raps.org/news-andarticles/2020/3/covid-19-vaccine-tracker

[38] Status of COVID-19 vaccines within WHO EUL-PQ evaluation process. WHO PQ 2021. www.extranet.who.int 